\title{
Erratum to: Algorithms for solutions of extended general mixed variational inequalities and fixed points
}

\author{
Javad Balooee • Yeol Je Cho
}

Published online: 23 March 2013

C Springer-Verlag Berlin Heidelberg 2013

\section{Erratum to: Optim Lett \\ DOI 10.1007/s11590-012-0516-2}

The original publication of the article contains errors which need to be amended as mentioned below:

(1) In Section 2, "Formulations and basic facts", lines 2 and 3, "Let $T, g, h: \mathcal{H} \rightarrow \mathcal{H}$ be three nonlinear single-valued operators" should be replaced by "Let $T, g, h$ : $\mathcal{H} \rightarrow \mathcal{H}$ be three nonlinear single-valued operators such that $g$ be an onto operator".

(2) In the problem (2.1), " $\rho \varphi(u)$ " must be changed to " $\rho \varphi(h(u))$ ".

(3) In Section 6, part "(III)" must be edited as below:

(III) Let the operators $T$ and $g$ be linear and suppose that the inverses of $T$ and $g$, that is, $T^{-1}$ and $g^{-1}$ exist. Then (6.1) can be written as follows:

$$
\begin{aligned}
T h^{-1} J_{\varphi}^{\rho} z+\rho^{-1} R_{\varphi} z=0 & \Leftrightarrow T\left(g^{-1}\left(z-R_{\varphi} z\right)\right)+\rho^{-1} R_{\varphi} z=0 \\
& \Leftrightarrow g^{-1}\left(z-R_{\varphi} z\right)=T^{-1}\left(-\rho^{-1} R_{\varphi} z\right) \\
& \Leftrightarrow z-R_{\varphi} z=g\left(-\rho^{-1} T^{-1} R_{\varphi} z\right)
\end{aligned}
$$

The online version of the original article can be found under doi:10.1007/s11590-012-0516-2.

J. Balooee $(\bowtie)$

Department of Mathematics, Sari Branch, Islamic Azad University, Sari, Iran

e-mail: javad.balooee@gmail.com

\section{Y. J. Cho}

Department of Mathematics Education and RINS,

Gyeongsang National University,

Chinju 660-701, Korea

e-mail: yjcho@gnu.ac.kr 


$$
\begin{aligned}
& \Leftrightarrow z=R_{\varphi} z-\rho^{-1} g T^{-1} R_{\varphi} z \\
& \Leftrightarrow z=\left(I-\rho^{-1} g T^{-1}\right) R_{\varphi} z .
\end{aligned}
$$

(4) In Algorithm 6.5, the iterative process " $z_{n+1}=\left(1-\alpha_{n}\right) z_{n}+\alpha_{n}(I-$ $\left.\rho^{-1} h T^{-1}\right) R_{\varphi} z_{n}$ ", must be replaced by " $z_{n+1}=\left(1-\alpha_{n}\right) z_{n}+\alpha_{n}(I-$ $\left.\rho^{-1} g T^{-1}\right) R_{\varphi} z_{n} "$

(5) In Algorithm 6.8, the iterative process " $z_{n+1}=\left(1-\alpha_{n}\right) z_{n}+\alpha_{n}(I-$ $\left.\rho^{-1} h T^{-1}\right) Q_{K} z_{n}$ ", should be replaced by " $z_{n+1}=\left(1-\alpha_{n}\right) z_{n}+\alpha_{n}(I-$ $\left.\rho^{-1} g T^{-1}\right) Q_{K} z_{n} "$

All the assertions are valid with these corrections. 